\title{
Mechanical characterization of limestone from sound velocity measurement
}

\author{
Thomas Parent ${ }^{a, b}{ }^{*}$, Nathalie Domede ${ }^{a}$, Alain Sellier ${ }^{a}$, Ludivine Mouatt ${ }^{b}$. \\ a Université de Toulouse; UPS, INSA; LMDC (Laboratoire Matériaux et Durabilité des Constructions); 135, avenue de \\ Rangueil; F-31 077 Toulouse Cedex 04, France \\ b Ginger CEBTP, 12 avenue Gay Lussac - ZAC La Clef Saint Pierre 78990 Elancourt, France \\ * Corresponding author \\ E-mail addresses: parent@insa-toulouse.fr (Thomas Parent), domede@insa-toulouse.fr (Nathalie Domede), \\ alain.sellier@insa-toulouse.fr (Alain Sellier)
}

\begin{abstract}
The aim of this research was to establish correlations between different physical properties (Sound velocity, $V_{p}$, bulk density, $\rho$, and open porosity, $P_{0}$ ) and mechanical properties (compressive strength, $R_{c}$, tensile strength, $R_{t}$, static elasticity modulus, $E_{0}$, and Poisson's ratio, $\nu$ ) of limestones. The first step of the work consisted in an experimental campaign on limestone cores drilled from a gothic building in Paris. Eight cores were extracted from the monument and tested in the laboratory. Secondly, the experimental results were added to those proposed by 14 authors in the international scientific literature and all of these data were analyzed using the generalized least-squares method so that correlation curves could be suggested. Seven correlations are proposed: $R_{c}-V_{P}, R_{c}-\rho, \rho-V_{p}, P_{0^{-}} \rho, E_{0}-R_{c}, \nu-V_{p}, R_{t}-R_{c}$. Finally, the dispersion of the results led to an estimated confidence level of $90 \%$ according to statistical considerations.
\end{abstract}

\section{Highlights}

- We carried out an experimental physical and mechanical campaign on limestones cores

- Correlations between different physical and mechanical properties are established.

- Dispersion of results led to an estimated confidence level according to statistical considerations

\section{Keyword}

Sound velocity, Limestones, Physical properties, Mechanical properties, Correlations 


\section{Introduction}

The present research studies the mechanical properties of rocks from a civil engineering point of view, taking particular interest in the preservation of architectural heritage. It deals with old monuments built with limestone masonry. The work was carried out in order to make a structural assessment of a gothic construction built in the center of Paris in the $13^{\text {th }}$ century (Old Refectory of the Saint-Martin des Champs priory -1230) (Fig. 1). The structural analysis of this monument required the mechanical properties of the limestone masonry to be known.
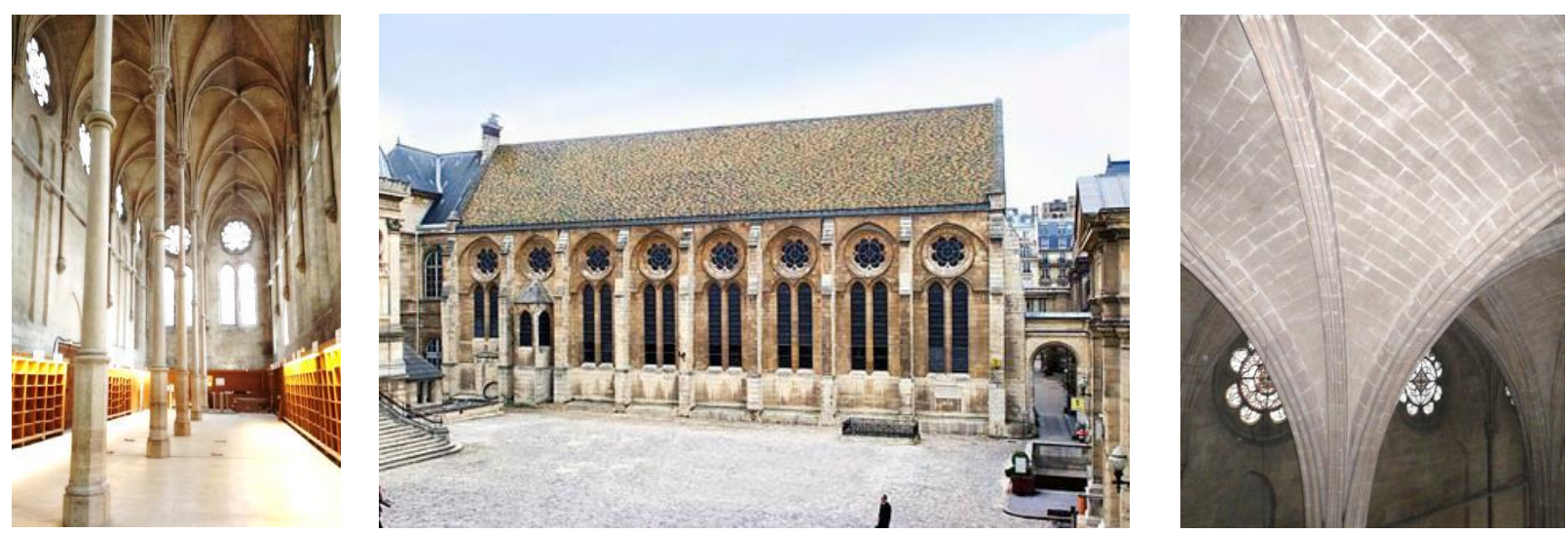

Fig. 1. Gothic construction: "Refectory of priory Saint Martin des Champs »

Masonry is a complex heterogeneous geomaterial composed of blocs bound together by mortar joints. Therefore, its mechanical characteristics depend both on the geometry and arrangement of the blocks and on the characteristics of each of the constituents. The present work focuses only on the main mechanical and physical characteristics of limestone blocks.

At construction time, the limestone was chosen carefully according to its structural role [1,2]. Therefore, in the monument, there are various distinct zones, where the materials have different mechanical qualities. Ultrasound velocity measurements carried out on the construction walls highlighted these different zones. However, the use of natural limestone implies that the characteristics of the blocks in a given zone may vary quite strongly because of the heterogeneity and diversity of the original quarries. Thus, for each area of the building, high variability of the mechanical properties was observed. The ideal would be to measure the mechanical characteristics and their variability using laboratory tests on samples drilled from the building. However, limits imposed on coring by the heritage character of the building and limits imposed on laboratory tests because of their cost led non-destructive measurement to be preferred whenever possible.

The mechanical properties of stones required to find the masonry constitutive law are numerous. The principal ones are: bulk density, $\rho$, compressive strength, $R_{c}$ (also noted UCS), tensile strength, $R_{t}$, static elasticity modulus, $E_{0}$, and Poisson's ratio, $\nu$. However, the velocity of the longitudinal sound wave, $V_{p}$, is easily obtained on site using ultrasonic test equipment such as a Pundit lab. This simple measurement becomes even more obviously indicated when we consider that many mechanical characteristics of limestone can be correlated with sound velocity [3-5] (in particular, bulk density and compressive strength). Thus, it seems interesting to propose improved correlation laws taking a large panel of limestones into account. 
In this article, first, an experimental campaign carried out on specimens drilled out of the monument is presented. Eight cores were analyzed. P wave sound velocity measurements were made on the building and on the samples. Then physical and mechanical tests were conducted on the cores, in the laboratory, in order to determine the following physical and mechanical characteristics: bulk density, $\rho$, open porosity, $P_{0}$, compressive strength, $R_{c}$, tensile strength, $R_{t}$, static elasticity modulus, $E_{0}$, and Poisson's ratio, $\nu$. Lastly, correlation laws were proposed on the basis of data obtained from 14 authors in the existing literature and from the results of the experimental campaign. The aim is to cover a wide and varied range of limestone types. Limestones identified in the literature review had densities ranging from $1250 \mathrm{~kg} / \mathrm{m} 3$ (soft limestone) to $2770 \mathrm{~kg} / \mathrm{m} 3$ (hard limestone). Seven correlations were found: $R_{c}-V_{P}, R_{c}-\rho, \rho-V_{p}, P_{0^{-}}$ $\rho, E_{0}-R_{C}, \nu-V_{p}, R_{T}-R_{c}$. Moreover, the proposed correlations are given with confidence level of 90 . Finally the results of these correlations are discussed.

\section{Literature review}

Data were collected from the work of 14 authors [3 - 18]. All data collected in the literature are shown in Fig. 5 to Fig. 11. On these figures, each point represents one rock type. It is the average of a minimum of 3 tests carried out on samples taken from the same stone layer, in the same quarry.

\subsection{Sound velocity tests}

In the field of civil engineering, the measurement of the velocity of a longitudinal sonic wave in a material is a widely used non-destructive test. It can be an indicator of the depth of a crack observed on the surface [19][20]. When this technique is coupled with sonic tomography, it can probe the interior of an element (wall or column) in order to study its composition or the presence of a possible defect [21][22]. Here, the aim of the study was to correlate the sound velocity with different mechanical properties.

Laboratory measurement of the velocity of an elastic longitudinal sound wave can be carried out using high and low frequency techniques or a resonance method $[23,24]$. However, no standard provides a test method for on-site measurement and it is generally assumed that correlations exist between sound velocity and compressive strength $[3,4,6,7,8,25]$.

\subsection{Bulk density}

The bulk density is relatively easy to measure. This data is essential for weight calculations. Moreover, it allows the compressive strength to be estimated via experimentally established correlations $[3,4]$.

\subsection{Compressive strength}

Knowledge of the compressive strength of limestones is essential if the structural behavior of masonry buildings, and particularly the structure failure mode, is to be assessed. This strength is measured by a uniaxial compressive test on a sample. Different standards are proposed internationally [26-28] and all recommend surfacing of the specimens and slow application of the loading force. However, the size of test specimens often differs and the compressive strength of a limestone specimen depends on (i) its size (scale effect) and (ii) its shape (slenderness ratio, cube or cylinder) $[29,30]$. This is why the shape and size of the specimens tested must be considered when the results are compared. The table of corrective factors applicable to compressive strength proposed in European standard EN 772-1 [26] was used in order to convert all the strength measurements to hypothetical values that would be obtained on 50 -mm-wide cylindrical or rectangular specimens with two slenderness ratios. This choice seems relevant because most tests were performed on samples of that size. Moreover the two slenderness ratios provide a quasiuniaxial compression state in the middle of the specimen and thus a measure of the intrinsic strength of 
the stone. This avoids having to consider the confinement induced by the friction between the cylinder and the plate of the press, which can lead to increased compressive strength values in specimens with lower slenderness.

\subsection{Tensile strength}

The compressive strength of the masonry depends partly on the tensile strength of the blocks that compose it [31], which can be obtained by direct tensile tests. This type of test is complex to achieve because it requires attaching the two opposite faces of the sample to the press in order to subject it to a displacement in the direction of pull. For this reason, numerous authors prefer indirect methods such as the split test or the three point bending test $[7,9]$. It should be noted that the tensile strengths obtained with these last tests are different from the direct uniaxial tensile strength values.

\subsection{Elastic characteristics $\mathrm{E}_{0}$ and $v$}

The static elasticity modulus and Poisson's ratio of limestones have not been subjected to as many tests as the compressive strength. This is explained by the fact that the mechanical tests for these characteristics are more difficult to perform (especially with the introduction of strain gauges on the sample). However, some authors propose measurement results for the elastic characteristics of limestone $[10,11,18]$. It is interesting to note that these tests were carried out on samples having 2 slenderness ratios.

\section{Experimental investigation carried out on the refectory and on laboratory}

\subsection{In situ sampling}

Eight cores were drilled from the monument. The cores were about $100 \mathrm{~mm}$ in diameter and $300 \mathrm{~mm}$ in length. Two distinct zones of the building were studied: Upper level walls (cores C11, C21, C23 and C31) and Base level walls (cores C41, C43, C51 and C53) (Fig 2.).
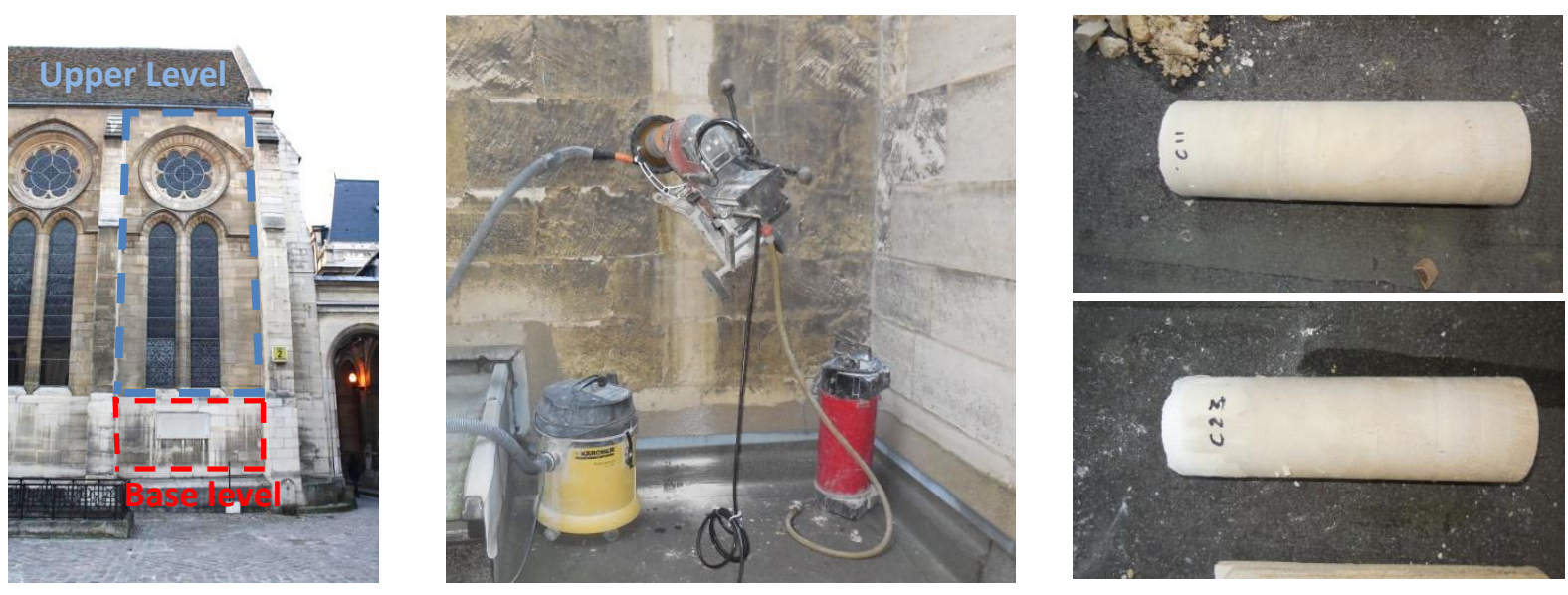

Fig 2. Cores drilled out on the monument

\subsection{Sound velocity measurement}

Sound velocity measurements were carried out firstly on the 8 blocks of the monument chosen for the coring operation. Secondly, laboratory measurements were made on the cores drilled from the blocks. The laboratory tests were carried out according to standard NF EN 14579 [24]. This standard requires a minimum of 6 measurements per sample. The laboratory measurements on cores were direct while 
measurements in situ were indirect. The results are presented in Table 1. The coefficient $\mu$ corresponds to the mean values of sound velocity and coefficient of variation of each group of four tests.

Table 1

Sound velocity measurement.

\begin{tabular}{|c|c|c|c|c|c|c|c|c|c|c|c|}
\hline \multirow{2}{*}{\multicolumn{2}{|c|}{ Sound Velocity measurements }} & \multicolumn{5}{|c|}{ Upper level } & \multicolumn{5}{|c|}{ Base level } \\
\hline & & C11 & C21 & $\mathrm{C} 23$ & C31 & $\mu$ & C41 & C43 & C51 & C53 & $\boldsymbol{\mu}$ \\
\hline \multirow[b]{2}{*}{ In situ } & Sound velocity (m/s) & 2509 & 3139 & 3257 & 2984 & 2972 & 3762 & 3937 & 3345 & 4415 & 3865 \\
\hline & $\begin{array}{l}\text { Coefficient of } \\
\text { variation (\%) }\end{array}$ & $5 \%$ & $8 \%$ & $3 \%$ & $4 \%$ & $5 \%$ & $6 \%$ & $9 \%$ & $4 \%$ & $7 \%$ & $6 \%$ \\
\hline \multirow{2}{*}{$\begin{array}{l}\text { In } \\
\text { laboratory } \\
\text { (on cores) }\end{array}$} & Sound velocity (m/s) & 2799 & 3064 & 3153 & 2895 & 2977 & 3951 & 4072 & 3982 & 4855 & 4215 \\
\hline & $\begin{array}{l}\text { Coefficient of } \\
\text { variation (\%) }\end{array}$ & $1 \%$ & $3 \%$ & $1 \%$ & $3 \%$ & $2 \%$ & $1 \%$ & $2 \%$ & $6 \%$ & $4 \%$ & $3 \%$ \\
\hline
\end{tabular}

The cores drilled from the upper level showed negligible deviation between sound velocities measured in situ $(2972 \mathrm{~m} / \mathrm{s})$ and those measured in the laboratory $(2977 \mathrm{~m} / \mathrm{s})$. However, this difference reached $7 \%$ for stones of the base level. This can be explained by the dispersion of results foreseeable when measurements are made on natural stone and also by differences in measurement procedures: firstly, measurements carried out on site are indirect whereas those conducted in the laboratory are direct and, secondly, the humidity and temperature conditions are not controlled on site.

Finally, a difference was observed in the sound velocity measured in the laboratory between base level stones (average: $3895 \mathrm{~m} / \mathrm{s}$, coefficient of variation: 5\%) and upper level stones (average: $2977 \mathrm{~m} / \mathrm{s}$, coefficient of variation: $10 \%)$.

\subsection{Bulk density and open porosity measurements}

Bulk density and open porosity of the samples were measured according to standard NF EN 1936 [32]. The results are shown in the Table 2 with mean values, $\mu$, and coefficient of variation, CV. Limestones sampled at the base level had a higher bulk density and a lower density than those of the upper level. This observation is consistent with the sound velocity measurements. 
Table 2

Bulk density and porosity measurement.

\begin{tabular}{|c|c|cc|}
\hline \multicolumn{2}{|c|}{} & $\begin{array}{c}\text { Bulk density } \\
\left(\mathrm{kg} / \mathrm{m}^{3}\right)\end{array}$ & Porosity (\%) \\
\hline \multirow{4}{*}{ Upper } & C11 & 1711 & 36.2 \\
Level & C21 & 1790 & 32.9 \\
& C23 & 1830 & 32.7 \\
& C31 & 1830 & 33.7 \\
\cline { 2 - 4 } & $\boldsymbol{\mu}$ & $\mathbf{1 7 9 0}$ & $\mathbf{3 3 . 9}$ \\
\cline { 2 - 4 } & $\mathrm{CV}$ & $\mathbf{3 . 1 \%}$ & $\mathbf{4 . 7 \%}$ \\
\hline \multirow{5}{*}{ Base Level } & $\mathrm{C41}$ & 2190 & 17.1 \\
& $\mathrm{C43}$ & 2230 & 16.7 \\
& $\mathrm{C51}$ & 2160 & 20.1 \\
& $\mathrm{C53}$ & 2460 & 4.6 \\
\cline { 2 - 4 } & $\boldsymbol{\mu}$ & $\mathbf{2 2 6 0}$ & $\mathbf{1 4 . 6}$ \\
\cline { 2 - 4 } & $\mathrm{CV}$ & $\mathbf{6 . 0 \%}$ & $\mathbf{4 6 \%}$ \\
\hline
\end{tabular}

\subsection{Measurements of elastic characteristics}

Six measurements of static elasticity modulus were carried out according to standard NF EN 14580 [33]. Three cores drilled at the base level (C43, C51 and C41) and three cores from the upper level (C11, $\mathrm{C} 21$ and C31) were characterized. The testing machine applied 3 cycles between the pre-load of $1.0 \mathrm{Mpa}$ and $33 \%$ of the estimated failure load. Core samples C11, C31, C43 and C53 were equipped with 2 vertical gauges and 2 longitudinal gauges. The measurements of radial strains gave an estimate of the Poisson's ratio of the 4 specimens. The stress-strain curves are shown in Fig. 3. Note that these specimens were not stressed to rupture during these tests.

The shape of the stress-strain curves shows quasi linear behavior of limestone between the pre-load and $33 \%$ of the failure load at the first loading cycle. Thus, no pre-damage, characterized by a loss of stiffness of the material, was observed in this strain interval. Table 3 indicates the values of elasticity modulus and Poisson's ratio of the tested samples. The average modulus was about $34.2 \mathrm{GPa}$ for the base level stones ( $C V=40 \%)$ and $10.8 \mathrm{GPa}$ for the upper level stones ( $\mathrm{CV}=20 \%)$. This observation is in line with sound velocity and compressive strength measurements: the base level stones were stiffer than the upper level stones. 


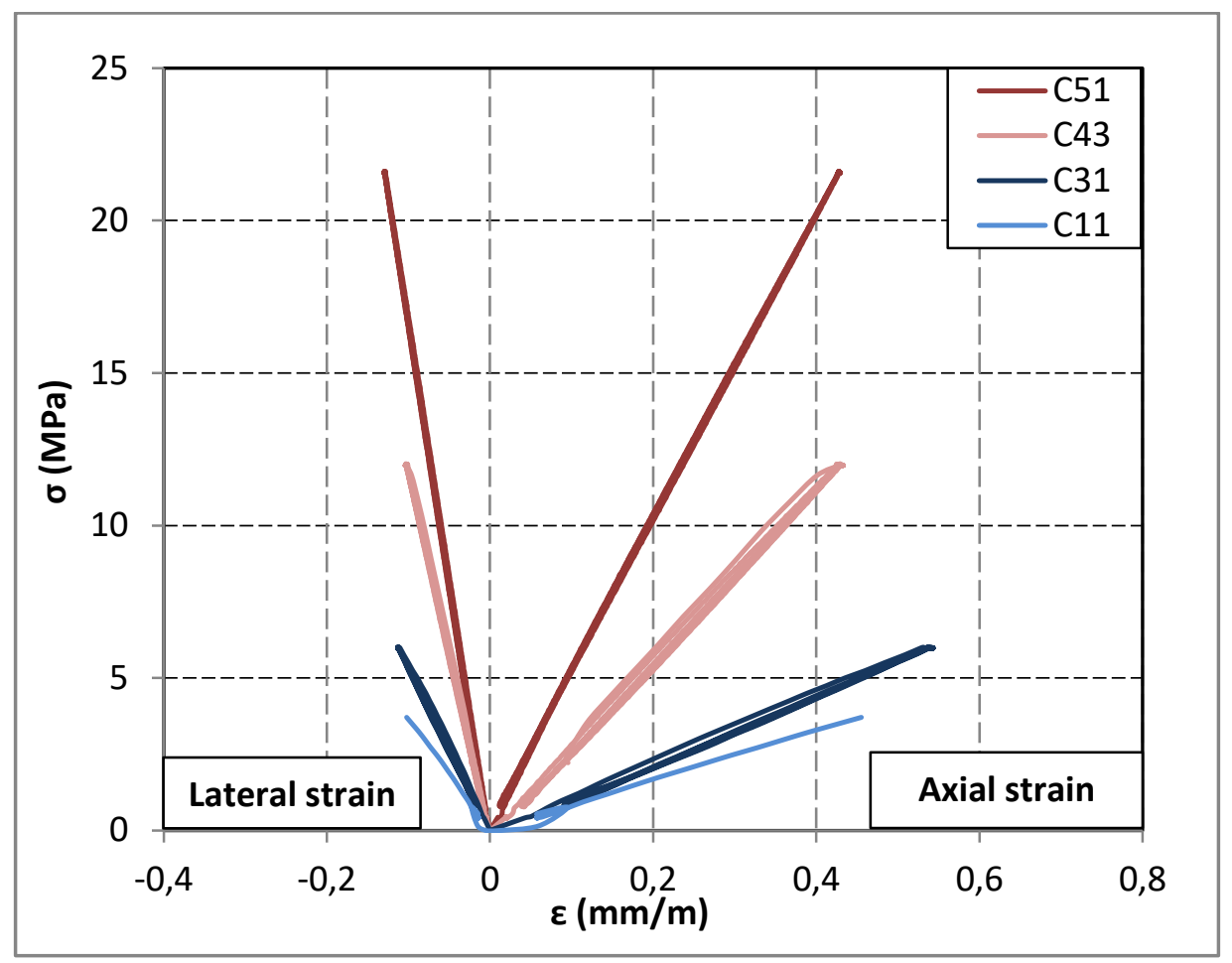

Fig. 3. Experimental elastic behaviour in compression

Table 3

Elastic properties of limestone.

\begin{tabular}{|c|ccc|c|c|ccc|c|c|}
\hline \multirow{2}{*}{$\begin{array}{c}\text { Elastic } \\
\text { properties }\end{array}$} & \multicolumn{4}{|c|}{ Upper Level } & \multicolumn{5}{c|}{ Base Level } \\
\cline { 2 - 10 } & C11 & C21 & C31 & $\boldsymbol{\mu}$ & CV (\%) & C41 & C43 & C53 & $\boldsymbol{\mu}$ & CV (\%) \\
\hline $\begin{array}{c}\text { Poisson Ratio } \boldsymbol{\nu} \\
\begin{array}{c}\text { Elasticity } \\
\text { Modulus (GPa) }\end{array}\end{array}$ & 0.22 & - & 0.21 & $\mathbf{0 . 2 1 5}$ & $\mathbf{3}$ & - & 0.24 & 0.29 & $\mathbf{0 . 2 6 5}$ & $\mathbf{1 3}$ \\
& 8.3 & 12.6 & 11.5 & $\mathbf{1 0 . 8}$ & $\mathbf{2 0}$ & 24.1 & 28.5 & 49.9 & $\mathbf{3 4 . 2}$ & $\mathbf{4 0}$ \\
\hline
\end{tabular}

\subsection{Mechanical behavior up to failure}

After the elasticity modulus tests, the four cores equipped with gauges (C11, C31, C43 and C53) were subjected to compression tests up to failure. The load was increased at a rate of $1 \mathrm{MPa} / \mathrm{s}$. The stress-strain curves are shown in Fig. 4. The compressive strength observed for the upper level cores (about $10 \mathrm{Mpa}$ ) was lower than that found for those of the base level (between 24 and $50 \mathrm{MPa}$ ). Moreover, it is interesting to note that the peak compressive strains for all specimens were relatively similar $(0.5 \mathrm{~mm} / \mathrm{m}$ for transversal strain and $1.6 \mathrm{~mm} / \mathrm{m}$ for longitudinal strains). In parallel, the other four cores were subjected to direct compressive tests to obtain their compressive strength. 


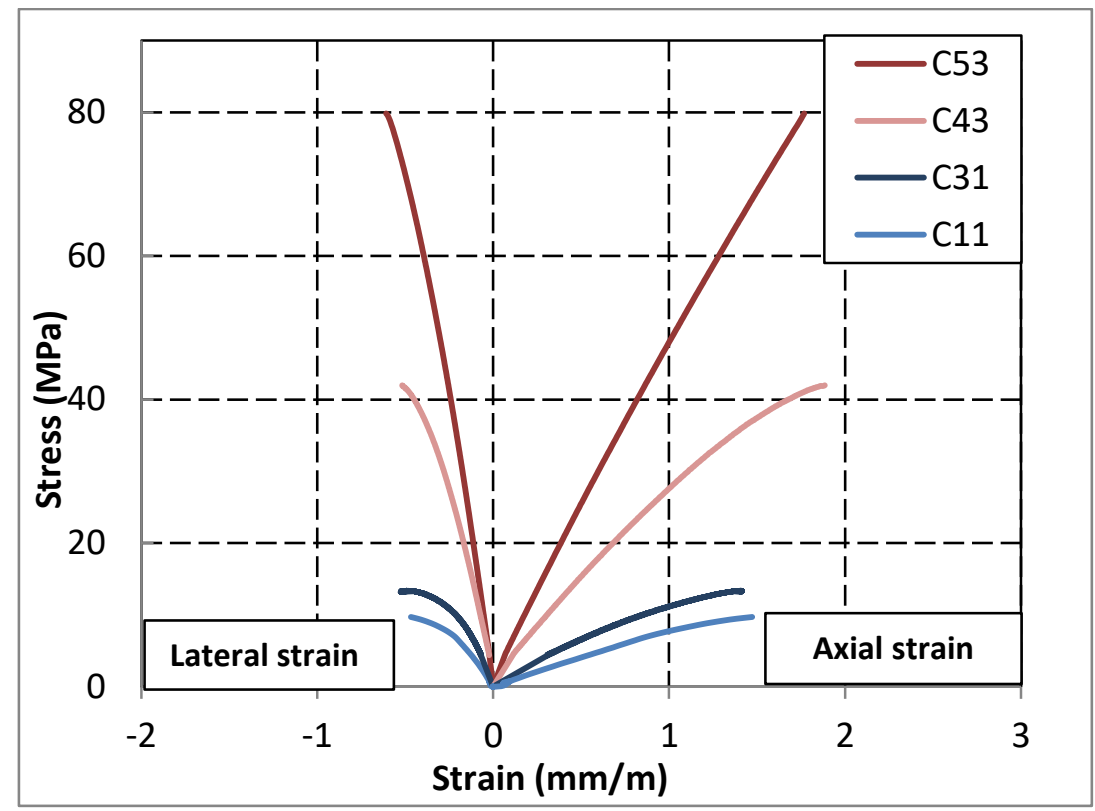

Fig. 4. Experimental compression behavior law

\subsection{Tensile strength tests}

Cores C23 and C51 were subjected to uniaxial tensile tests. The tensile strength was about $2.0 \mathrm{MPa}$ for core C23 and 4.5 MPa for core C51.

\subsection{Summary of experimental results}

Table 4 summarizes the data obtained during the experimental campaign. Note that the missing values are due to limitations of the tests on each core. The standard requires a minimum slenderness ratio of about 2 for elasticity modulus measurements. The average length of cores was about $300 \mathrm{~mm}$ and their diameter was about $100 \mathrm{~mm}$. Thus, it was not possible to perform all the required mechanical tests.

\section{Table 4}

Summary of experimental results.

\begin{tabular}{|c|c|c|c|c|c|c|c|c|c|}
\hline & & $\begin{array}{c}V_{p} \\
(m / s)\end{array}$ & $\begin{array}{c}\rho \\
\left(\mathrm{kg} / \mathrm{m}^{3}\right) \\
\end{array}$ & $\begin{array}{c}\mathrm{P}_{0} \\
(\%)\end{array}$ & $\begin{array}{c}R_{c} \\
(\mathrm{MPa}) \\
\end{array}$ & $\begin{array}{c}\mathrm{R}_{\mathrm{T}} \\
(\mathrm{MPa})\end{array}$ & $\begin{array}{c}E_{0} \\
(\mathrm{GPa})\end{array}$ & $v$ & $\begin{array}{c}\varepsilon_{\mathrm{pc}} \\
(\mathrm{mm} / \mathrm{m})\end{array}$ \\
\hline \multirow{6}{*}{$\begin{array}{l}\text { Upper } \\
\text { Level }\end{array}$} & C11 & 2799 & 1711 & 36.2 & 9.7 & - & 8.3 & 0.22 & 1.5 \\
\hline & C21 & 3064 & 1790 & 32.9 & 10.0 & - & 12.6 & - & - \\
\hline & C23 & 3153 & 1830 & 32.7 & 13.0 & 2.0 & - & - & - \\
\hline & C31 & 2895 & 1830 & 33.7 & 13.3 & - & 11.5 & 0.21 & 1.4 \\
\hline & $\mu$ & 2978 & 1790 & 33.9 & 11.5 & 2 & 10.8 & 0.215 & 1.45 \\
\hline & CV (\%) & $5.4 \%$ & $3.1 \%$ & $4.8 \%$ & $16.6 \%$ & - & $20.7 \%$ & $3.3 \%$ & $4.9 \%$ \\
\hline \multirow{6}{*}{ Base Level } & C41 & 3951 & 2190 & 17.1 & 46.5 & - & 24.1 & - & - \\
\hline & C43 & 4072 & 2230 & 16.7 & 41.9 & - & 28.5 & 0.24 & 1.8 \\
\hline & C51 & 3982 & 2160 & 20.1 & 45.5 & 4.5 & - & - & - \\
\hline & C53 & 4855 & 2460 & 4.6 & 79.9 & - & 49.9 & 0.29 & 1.75 \\
\hline & $\mu$ & 4215 & 2260 & 14.6 & 53.3 & 4.5 & 34.2 & 0.265 & 1.775 \\
\hline & CV (\%) & $10.2 \%$ & $6.0 \%$ & $46.9 \%$ & $33.2 \%$ & - & $40.4 \%$ & $13.3 \%$ & $2.0 \%$ \\
\hline
\end{tabular}




\section{Correlation laws}

A series of 7 correlation curves is proposed here. The relations are summarized in Table 5 and plotted on Fig. 5 to Fig. 11. The laws were obtained by minimizing the error between the experimental and theoretical values (generalized least-squares method). Each point corresponds to a group of specimens taken from the same quarry layer. For each point, the error minimization is weighted by the number of specimens. The main criterion for the choice of type of mathematical function is the minimization of the weighted error between the theoretical value and the experimental value. For each correlation, 2 dotted curves delimit the interval of variation around the theoretical value with a confidence level of $90 \%$. This interval is based on the calculation of the coefficient of variation, $\mathrm{CV}$, of experimental values normalized by the theoretical value. A normal distribution of the population is assumed here. Moreover, CV is an interesting indicator of the dispersion of experimental values with respect to the theoretical value defined by the correlation function.

\section{Table 5}

Summary of correlation laws.

\begin{tabular}{|c|c|c|c|c|c|c|}
\hline Parameters & Correlation curves & $\begin{array}{c}\text { Number of } \\
\text { different stones }\end{array}$ & $\begin{array}{c}\text { Total number } \\
\text { of specimens }\end{array}$ & $\mathbf{C V}$ & $\mathbf{R}^{2}$ & Figure \\
\hline $\boldsymbol{R}_{\boldsymbol{c}}(\mathrm{MPa})-\boldsymbol{V}_{\boldsymbol{P}}(\mathrm{m} / \mathrm{s})$ & $R_{C}=5.61 * 10^{-9} V_{p}^{2.75}$ & 215 & 1150 & $34 \%$ & 0.86 & 5 \\
\hline $\boldsymbol{R}_{\boldsymbol{c}}(\mathrm{MPa})-\boldsymbol{\rho}\left(\mathrm{kg} / \mathrm{m}^{3}\right)$ & $R_{C}=0.144 * \mathrm{e}\left(2,50.10^{-3} * \rho\right)$ & 220 & 1150 & $36 \%$ & 0.80 & 6 \\
\hline $\boldsymbol{\rho}\left(\mathrm{kg} / \mathrm{m}^{3}\right)-\boldsymbol{V}_{\boldsymbol{p}}(\mathrm{m} / \mathrm{s})$ & $\rho=946 \ln \left(V_{P}\right)-5561$ & 220 & 1150 & $6 \%$ & 0.84 & 7 \\
\hline $\boldsymbol{P}_{\boldsymbol{0}}(\%)-\boldsymbol{\rho}\left(\mathrm{kg} / \mathrm{m}^{3}\right)$ & $P_{0}=-3.68 * 10^{-2} \rho+99.5$ & 119 & 650 & $2 \%$ & 0.99 & 8 \\
\hline $\boldsymbol{E}_{\boldsymbol{O}}(\mathrm{GPa})-\boldsymbol{R}_{\boldsymbol{C}}(\mathrm{MPa})$ & $E_{0}=0.965 V_{p}^{0.810}$ & 30 & 98 & $37 \%$ & 0.77 & 9 \\
\hline $\boldsymbol{\nu}-\boldsymbol{V}_{\boldsymbol{p}}(\mathrm{m} / \mathrm{s})$ & $v=0.152 V_{p}^{0.126}$ & 15 & 43 & $10 \%$ & 0.67 & 10 \\
\hline $\boldsymbol{R}_{\boldsymbol{T}}(\mathrm{MPa})-\boldsymbol{R}_{\boldsymbol{c}}(\mathrm{MPa})$ & $R_{T}=3.84 \ln \left(R_{C}\right)-6.49$ & 35 & 90 & $34 \%$ & 0.73 & 11 \\
\hline
\end{tabular}

The first three correlations between uniaxial compressive strength, bulk density and ultrasonic velocity are each based on more than 200 different stones, and about 1150 samples. They present correlation coefficients $\mathrm{R}^{2}$ of $0.86,0.80$ and 0.84 respectively for the correlations $R_{c}-V_{P}, R_{c}-\rho$, et $\rho-\mathrm{Vp}$.

The relation between bulk density $\rho$ and porosity $P_{0}$ is linear and its correlation coefficient is about 0.99. In fact, porosity $P_{0}$, bulk density $\rho$ and particle density $\rho_{\text {particle }}$ are linked by Eq. 1 . It is verified that, for a porosity of $100 \%$, the bulk density is nearly zero and for a porosity equal to $0 \%$, the bulk density reaches the density of pure calcite $\left(\rho_{\text {calcite }}=2780 \mathrm{~kg} / \mathrm{m}^{3}\right)$. The correlation coefficient near to 1 $\left(R^{2}=0.99\right)$ supports the conclusion that knowing the bulk density of a limestone enable the open porosity to be estimated with a relative error of $2 \%$. Finally, the coefficients of the linear equation of $100 \%$ and the value of $\rho_{\text {calcite }}$ confirm that all the stones studied consisted predominantly of calcite.

$$
P_{0}=1-\frac{\rho}{\rho_{\text {particle }}}
$$


The last three correlations $E_{0}-V_{p}, \nu-V_{p}$ and $R_{t}-R_{c}$ present correlation coefficients $\mathrm{R}^{2}$ of $0.77,0.67$ and 0.73. However, data for establishing these equations were more limited (between 15 and 35 types of rock).

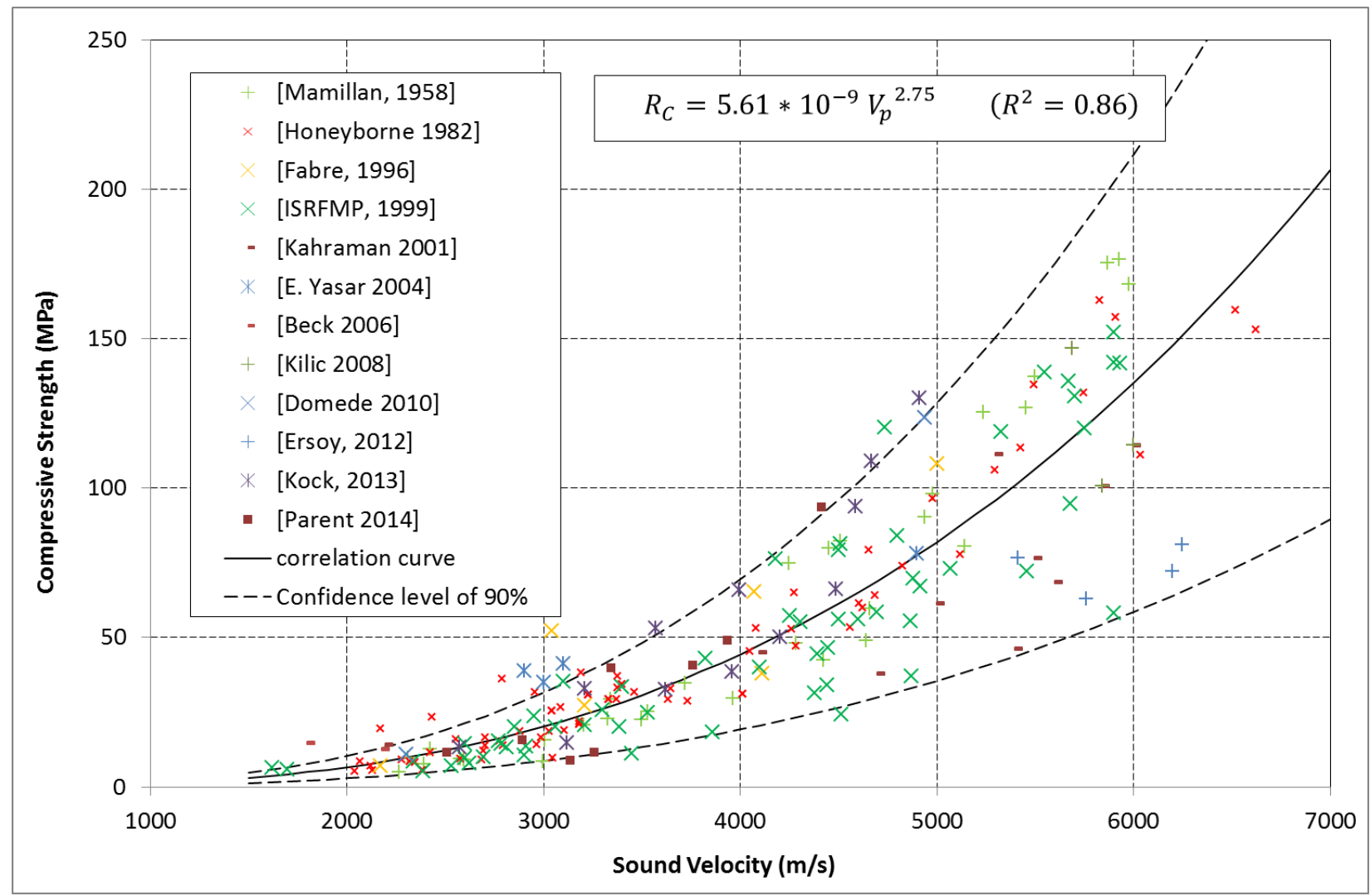

Fig. 5. Correlation between Compressive strength and Sound velocity. 


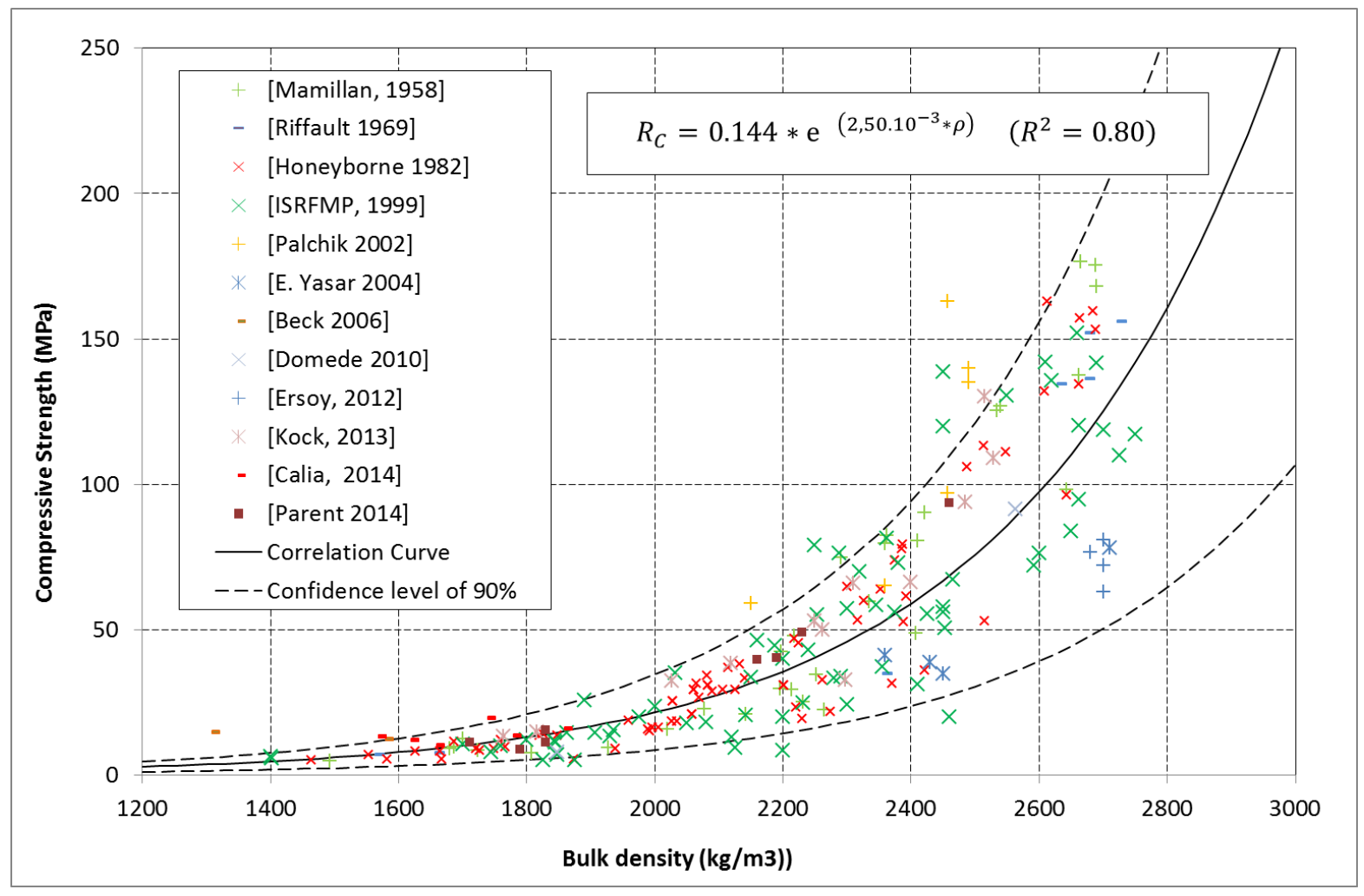

Fig. 6. Correlation between Compressive strength and Bulk density.

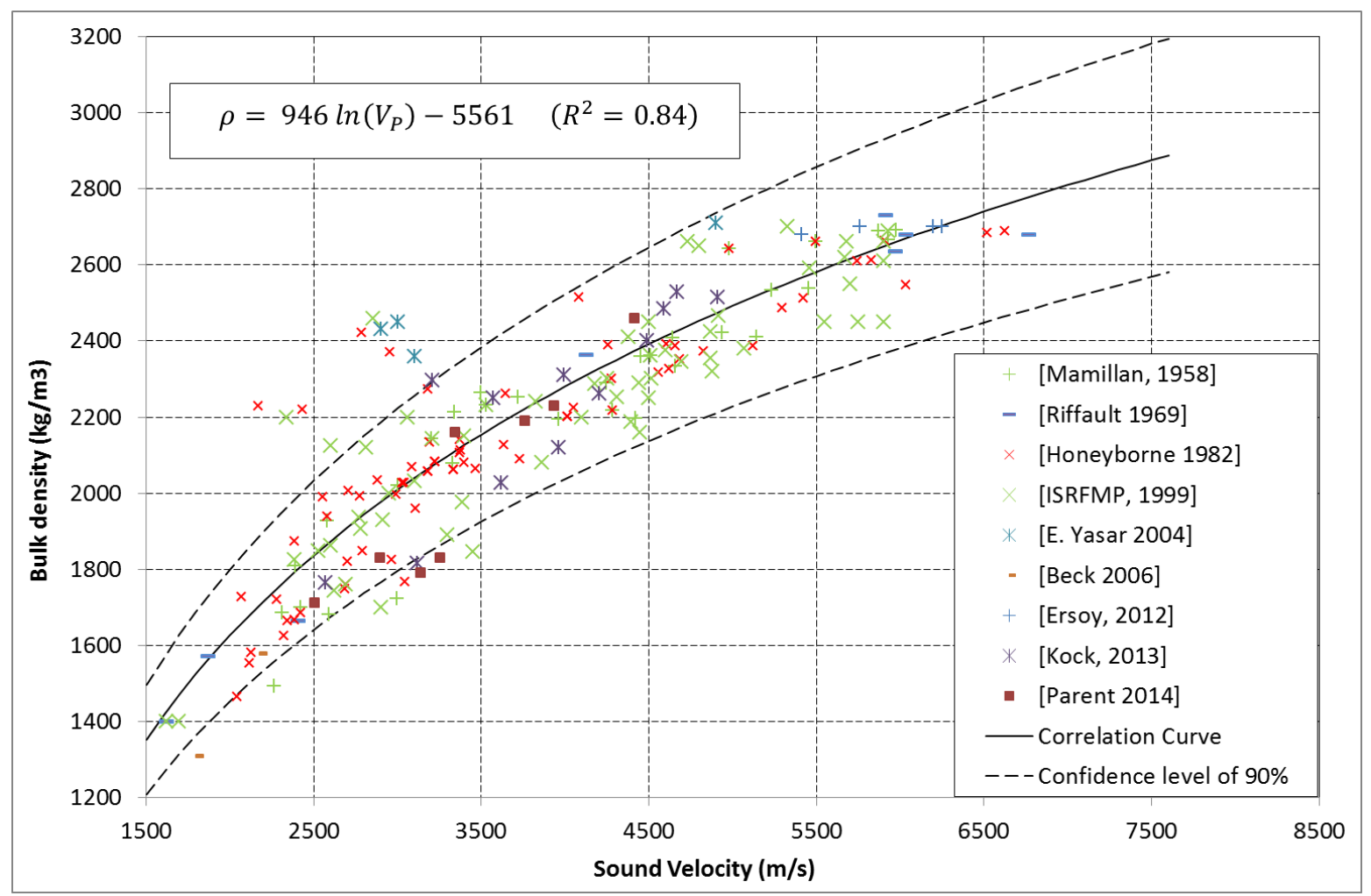

Fig. 7. Correlation between bulk density and Sound velocity. 


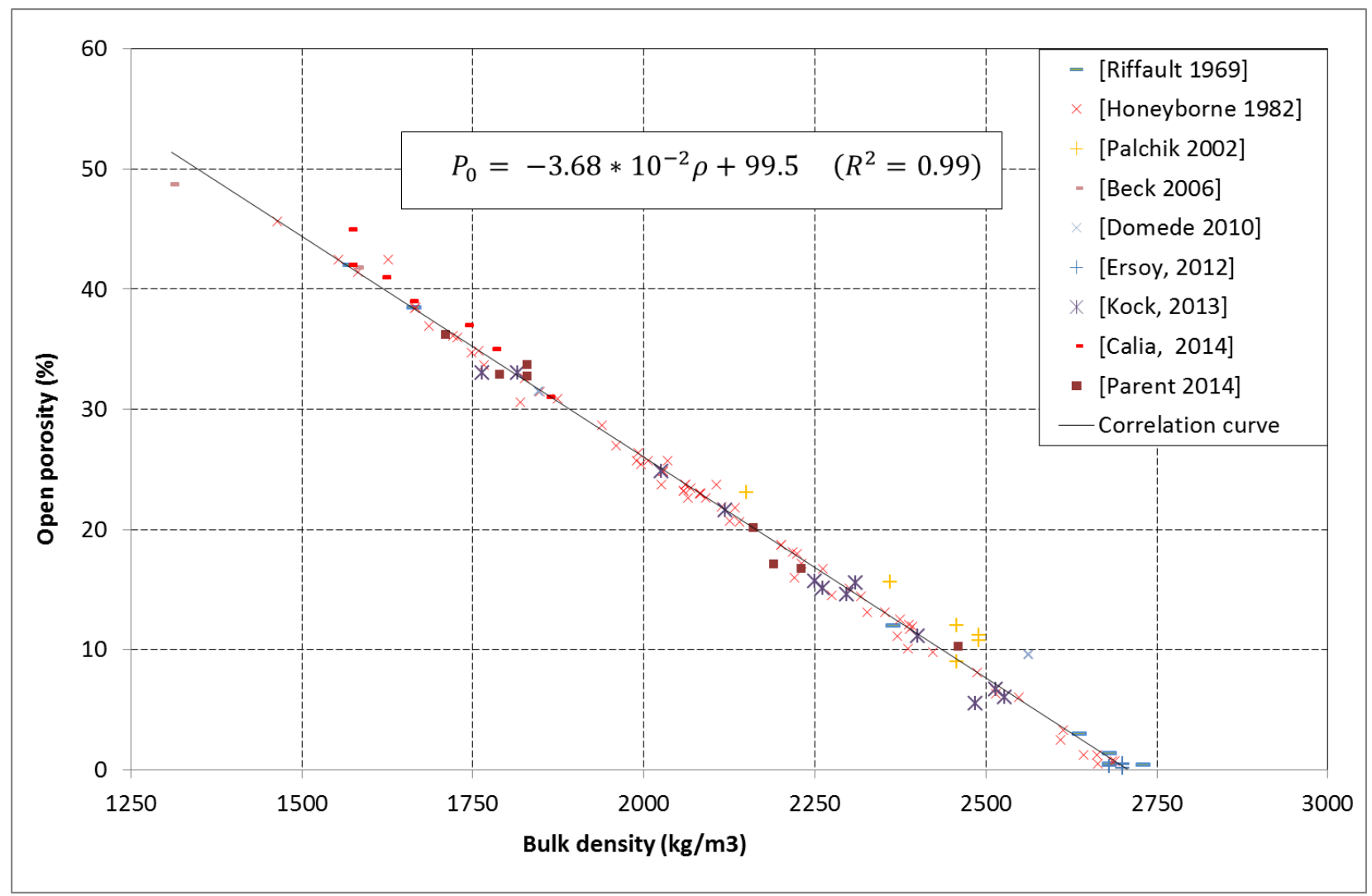

Fig. 8. Correlation between Porosity and Bulk density.

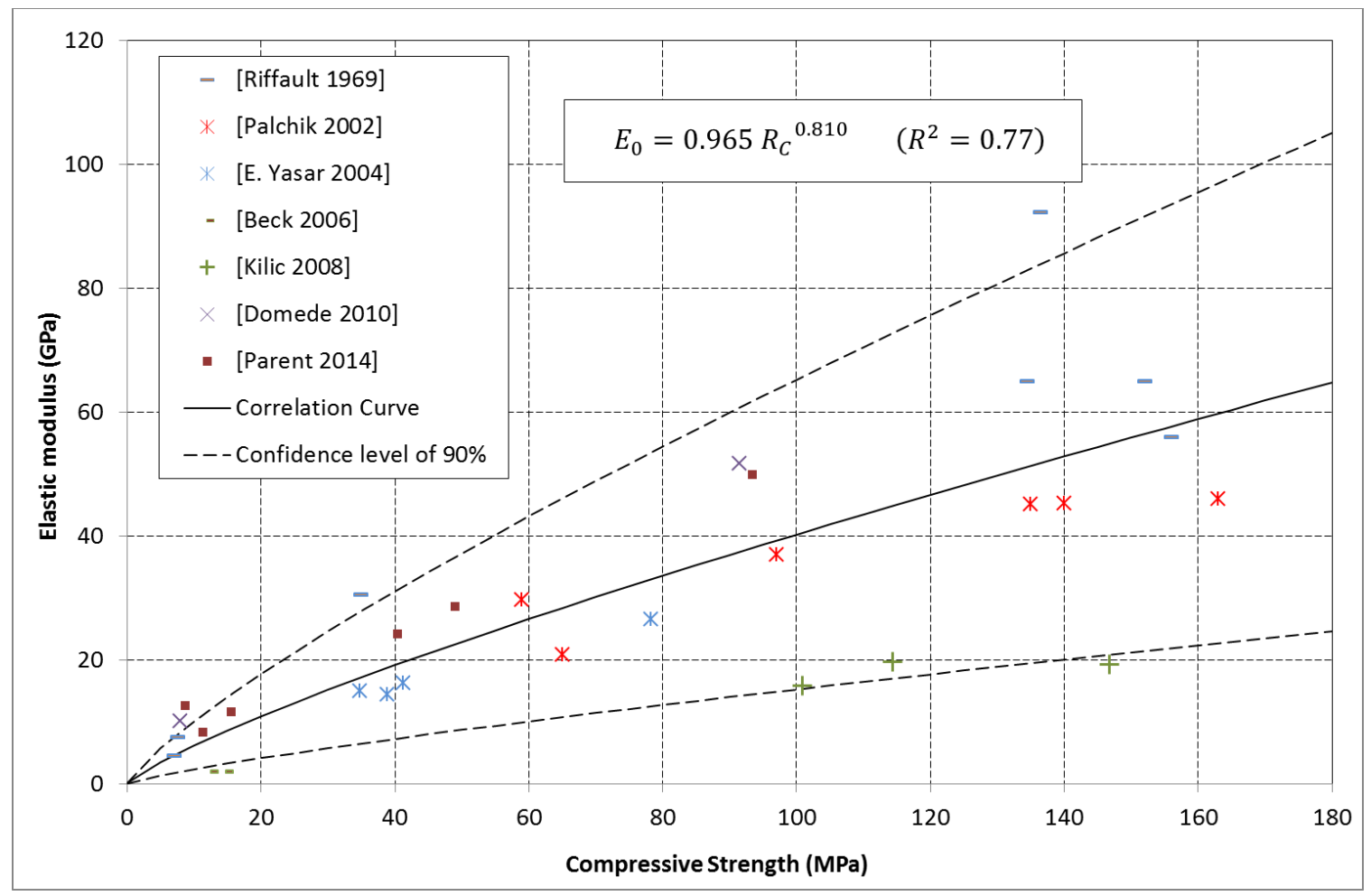

Fig. 9. Correlation between Elastic modulus and Compressive strength. 


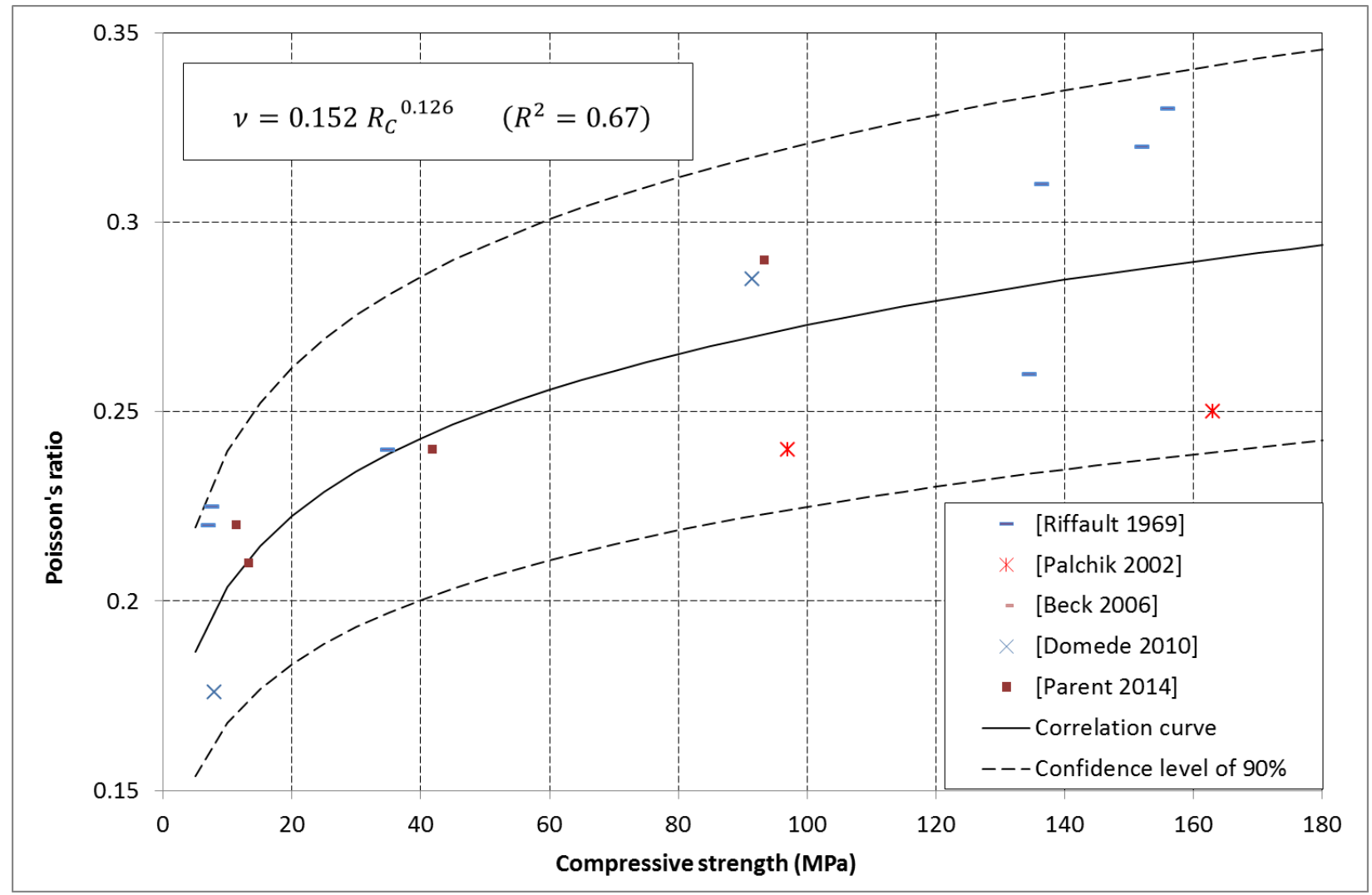

Fig. 10. Correlation between Poisson's ratio and Compressive strength. 


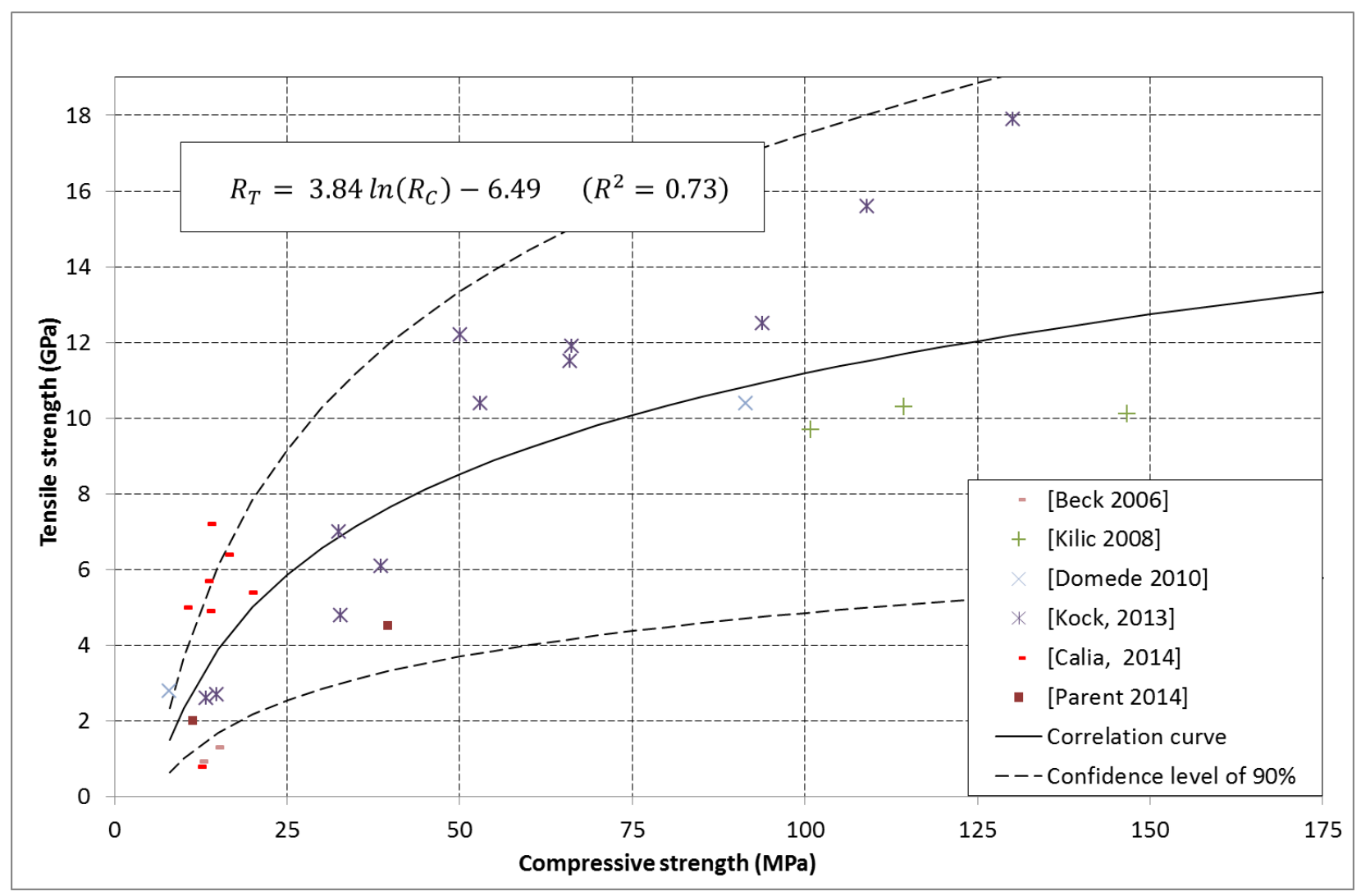

Fig. 11. Correlation between Tensile strength and Compressive strength.

\section{Conclusion}

Experimental tests were carried out to determine the mechanical characteristics $\left(R_{t}, R_{\mathrm{c}}, E_{0}\right.$ and $\left.\nu\right)$ and physical properties $\left(P_{0}\right.$ and $\left.V_{P}\right)$ of limestone cores drilled from a Parisian gothic building. The results of the experimental campaign were combined with mechanical and physical data for limestones proposed by 14 authors published in the international scientific literature. The large number of samples coming from different quarries in the world led us to consider a wide range of calcareous stone (bulk density from 1300 $\mathrm{kg} / \mathrm{m} 3$ to $2770 \mathrm{~kg} / \mathrm{m} 3$ ). Correlation laws are proposed from those data.

The relations have various forms:

- Power function of the form $y=a x^{b}$ for the $R_{c}-V_{p}, E_{0}-R_{c}$ and $\nu-R_{c}$ relations.

- Exponential function of the form $y=a e^{b x}$ for the $R_{C}-\rho$ relation.

- Logarithmic function of the form $y=a \ln (x)+b$ for the $\rho-V_{p}$ and $R_{t}-R_{c}$. relations

- Linear function of the form $y=a x+b$ pour for the $P_{0^{-}} \rho$ relation.

In terms of dispersion, the correlations $R_{C} . V_{P}, R_{C}-\rho, E_{0}-R_{C}$ and $R_{T}-R_{C}$ present coefficients of variation CV of $34 \%, 36 \%, 37 \%$ and $34 \%$ respectively. These significant dispersions resulted in a large confidence level being obtained. Inversely, correlations $\rho-V_{p}, P_{0}-\rho$ and $\nu-R_{C}$ present coefficients of variation lower than $10 \%$, leading to a lower confidence level of $90 \%$. 
Finally, the proposed correlations allow many mechanical characteristics useful for the scientific assessment of historical monuments to be obtained from simple in situ non-destructive tests based on measurements of the velocity of sound. Thanks to these data, non-linear mechanical analyses can be carried out in order to assess the strength capacity of a damaged structure and objectively analyze the efficiency of a repair solution.

\section{Acknowledgments}

This study was party supported by the Ginger CEBTP Company. The authors would like to thank Martin Brunel, the architect in charge of the refectory of Saint Martin des Champs, and David Zakharief, director of heritage at the Conservatoire National des Arts et Métiers. The authors would also like to thank ISRFMP for providing us with their database on the mechanical characteristics of limestone. 


\section{References}

[1] Abraham P, Viollet-Le-Duc et le rationalisme médiéval. Vincent, Fréal \& Cie, 1934.

[2] Viollet-le-Duc EE, Dictionnaire raisonné de l'architecture française du XIe au XVIe siècle. B. Bance, 1859.

[3] Mamillan M, Méthode de classification des pierres calcaires, Ann. Inst. Tech. Bâtim. Trav. Publics, $\mathrm{n}^{\mathrm{o}} 125,1958$, p. 469-525.

[4] Basem Moh'd K, Compressive Strength of Vuggy Oolitic Limestones as a Function of Their Porosity and Sound Propagation, Jordan J. Earth Environ. Sci., 2009, vol. 2, n 1, p. 18-25.

[5] Kahraman S and Yeken T, Determination of physical properties of carbonate rocks from P-wave velocity, Bull. Eng. Geol. Environ., 2008, vol. 67, nº 2, p. 277-281.

[6] Kahraman S, "Evaluation of simple methods for assessing the uniaxial compressive strength of rock", Int. J. Rock Mech. Min. Sci., 2001, vol. 38, nº 7, p. 981-994.

[7] Kılıç A and Teymen A, Determination of mechanical properties of rocks using simple methods, Bull. Eng. Geol. Environ. , 2008, vol. 67, n² 2, p. 237-244.

[8] Yasar E and Erdogan Y, Correlating sound velocity with the density, compressive strength and Young's modulus of carbonate rocks, Int. J. Rock Mech. Min. Sci., 2004, vol. 41, no 5, p. 871-875.

[9] Beck K, Étude des propriétés hydriques et des mécanismes d'altération de pierres calcaires à forte porosité, Phd thesis, Université d'Orléans, 2006.

[10] Riffault, Catalogue des caractéristiques géologiques et mécaniques de quelques roches françaises. Laboratoire Central des Ponts et Chaussées, 1999.

[11] Domede N, Caractérisation expérimentale de deux pierres naturelles de construction, Annual conference of Association Universitaire de Génie Civil, France 2010.

[12] Honeyborne DB , The building limestones of France. London: Dept. of the Environment, Building Research Establishment: H.M.S.O, 1982.

[13] Fabre D and Gustkiewicz J, Poroelastic properties of limestones and sandstones under hydrostatic conditions, Int. J. Rock Mech. Min. Sci. , 1997, vol. 34, nº 1, p. 127-134.

[14] Ersoy $\mathrm{H}$ and Kanik D, Multicriteria decision-making analysis based methodology for predicting carbonate rocks' uniaxial compressive strength, EARTH Sci. Res. J., 2012, vol. 16, nº 1, p. 65-74.

[15] Kock TD, Dewanckele J, Boone M, Schutter GD, Jacobs P, and Cnudde V, Replacement stones for Lede stone in Belgian historical monuments, Geol. Soc. Lond. Spec. Publ., 2013, vol. 391, p. 391-399.

[16] Calia A, Tabasso ML, AM Mecchi, and Quarta G, The study of stone for conservation purposes: Lecce stone (southern Italy), Geol. Soc. Lond. Spec. Publ., 2013, vol. 391, p. SP391.8.

[17] ISRFMP, CD-Rom : Mémoire de Pierre. Association Ouvrière des Compagnons du Tour de France, 1999.

[18] Palchik V and Hatzor YH, Crack damage stress as a composite function of porosity and elastic matrix stiffness in dolomites and limestones, Eng. Geol. , 2002, vol. 63, n 3-4, p. 233-245.

[19] Grecchi G, Monitoring and Structural Assessment of Monuments in the Historical Centre of L'Aquila struck by the 2009 Earthquake: the Case Study of St. Silvestro Church Italy, Italy, 2012. 
[20] Faella G, Frunzio G, Guadagnuolo M, Donadio A, and Ferri L, The Church of the Nativity in Bethlehem: Non-destructive tests for the structural knowledge, Church Nativ. Bethlehem Interdiscip. Approach Knowl.-Based Restor. , 2012, vol. 13, n 4, Supplement, p. e27-e41.

[21] Binda L, Saisi A, and Zanzi L, Sonic tomography and flat-jack tests as complementary investigation procedures for the stone pillars of the temple of S. Nicolò l'Arena (Italy), NDT E Int. , 2004, vol. 36, $\mathrm{n}^{\circ}$ 4, p. 215-227.

[22] Schuller MP, Nondestructive testing and damage assessment of masonry structures, Prog. Struct. Eng. Mater. , 2003, vol. 5, nº 4, p. 239-251.

[23] ISRM, Basic geotechnical description of rock masses, Int. J. Rock. Mech. Min. Sci. Geomech. Abstr., 1981.

[24] NF EN 14579, Méthodes d'essai pour pierres naturelles. Détermination de la vitesse de propagation du son, AFNOR. 2005.

[25] Sharma PK and Singh TN, "A correlation between P-wave velocity, impact strength index, slake durability index and uniaxial compressive strength", Bull. Eng. Geol. Environ. , 2008, vol. 67, n 1, p. 1722.

[26] NF EN 772-1, Méthodes d'essai des éléments de maçonnerie - Partie 1: détermination de la résistance à la compression, AFNOR, 2011.

[27] D18 Committee, Test Method for Unconfined Compressive Strength of Intact Rock Core Specimens, ASTM International, 2002.

[28] ISRM, Rock characterization testing and monitoring, Oxford: Pergamon Press, 1981.

[29] Mohammed A, Hughes TG, and Mustapha A, The effect of scale on the structural behaviour of masonry under compression, Constr. Build. Mater. , 2011, vol. 25, nº 1, p. 303-307.

[30] Thuro K, Plinninger RJ, Zäh S, and Schütz S, Scale effects in rock strength properties. Part 1: Unconfined compressive test and Brazilian test, ISRM Regional Sympsosium, Eurock 2001, Espoo, Finland, 2001.

[31] Lourenço PB and Pina-Henriques J, Validation of analytical and continuum numerical methods for estimating the compressive strength of masonry, Comput. Struct. , 2006, vol. 84, nº 29-30, p. 1977-1989.

[32] NF EN 1936, Détermination des masses volumiques réelle et apparente et des porosités ouverte et totale. AFNOR, 2007.

[33] NF EN 14580, Méthode d'essai pour pierres naturelles, Détermination du module d'élasticité statique .AFNOR, 2005. 